Article

\title{
Agricultural Tractor Roll-Over Related Fatalities in Italy: Results from a 12 Years Analysis
}

\author{
Davide Facchinetti (D), Stefano Santoro (D), Lavinia Eleonora Galli and Domenico Pessina *(D) \\ Dipartimento di Scienze Agrarie e Ambientali, Università degli Studi, 20122 Milan, Italy; \\ davide.facchinetti@unimi.it (D.F.); stefano.santoro@unimi.it (S.S.); lavinia.galli@unimi.it (L.E.G.) \\ * Correspondence: domenico.pessina@unimi.it; Tel.: +39-02-50316876
}

check for updates

Citation: Facchinetti, D.; Santoro, S.; Galli, L.E.; Pessina, D. Agricultural Tractor Roll-Over Related Fatalities in Italy: Results from a 12 Years Analysis. Sustainability 2021, 13, 4536. https://doi.org/10.3390/su13084536

Academic Editors: Mara Lombardi,

Fatma El Zahraa Ashour,

Massimo Guarascio and

Mario Fargnoli

Received: 20 March 2021

Accepted: 16 April 2021

Published: 19 April 2021

Publisher's Note: MDPI stays neutral with regard to jurisdictional claims in published maps and institutional affiliations.

Copyright: (c) 2021 by the authors. Licensee MDPI, Basel, Switzerland. This article is an open access article distributed under the terms and conditions of the Creative Commons Attribution (CC BY) license (https:/ / creativecommons.org/licenses/by/ $4.0 /)$.

\begin{abstract}
In Italy, about 160 fatal accidents per year have occurred recently in agriculture, most of them involving agricultural machinery. The most frequent cause of fatal events is the tractor overturning. One of the opportunities to monitor the trend of agricultural tractors fatal overturning is a meticulous search for information on the numerous web portals, at national and local level. In fact, in their information purposes are also included the recording, practically in real time, of significant details about each fatal event, such as the place of the accident, the year, the month and the day of the week of occurring, the victim's age, gender and nationality, etc. This article is describing the results of the monitoring of fatal tractor overturning accidents in the period of 2008-2019 in Italy. In the 12 years of the survey, 1414 fatal accidents were recorded, most of them occurring in the spring and summer months. The region with the highest cumulative number of fatal events was Tuscany (143). The majority ( $58.8 \%$ ) of the victims were over 60 , while $71.4 \%$ of accidents occurred during field work. Most $(57.6 \%)$ of the tractors involved in the fatal events did not have rollover protective structures (ROPS), while $19.4 \%$ were equipped with a two-post foldable front roll-bar, which, however, was in the lowered position at the time of the accident. In most cases, the tractors involved were obsolete and in poor maintenance conditions, and did not comply with general and specific laws on work safety. To improve the situation, the introduction of the tractor training certificate for the drivers and the periodical inspection for tractors, as well as the issuing of significant financial supports to encourage the replacement of the old models with modern more safe models, are the most effective actions to be put into practice.
\end{abstract}

Keywords: safety; fatal accident; ROPS; web monitoring

\section{Introduction}

In Italy, the gloomy record of the highest number of fatal accidents at work has always been disputed among the manufacturing, agricultural, and construction sectors. In the 5-year period of 2015-2019, 990 and 877 fatal events were recorded in Italy by INAIL (National Institute for Insurance Against Accidents at Work) [1], respectively, for the manufacturing and construction sectors, compared to 788 fatal accidents in the agricultural sector. Most of the fatal events in agriculture occur during the use of machinery, in particular, in the use of the tractor, very frequently by its overturning [2].

Rondelli et al. [3] report that out of 817 fatal accidents in Italy in the agricultural sector occurred between 2002 and 2012, 357 (43.7\%) involved tractors, including 205 accidents due to overturning (57.4\%). Myers et al. [4] report that 1538 fatal events were recorded in the United States between 1992 and 2007 as a result of tractor overturning. In addition, in the United States, Helmkamp and Lundstrom [5] report that more than $75 \%$ of fatal accidents between 1997 and 2002 in West Virginia were caused by tractor overturning. In

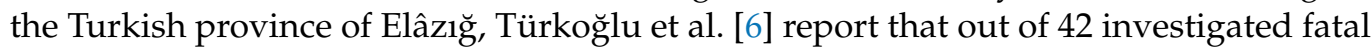
events, those caused by tractor overturning, concern $42.9 \%$ of cases. Still in Turkey, in an analysis of 41 tractor-related fatalities reported between 2006 and 2009 by First Specialty 
Board of Council of Forensic Medicine (FSBCFM), 34.1\% of these were caused by tractor overturning [7].

Injuries caused by overturning can be limited by installing appropriate rollover protective structures (ROPS) together with a safety belt fixed to the driver's seat [8], but not all tractors are properly equipped. According to Reynolds and Groves [9], in the United States up to the year 2000 , only $50 \%$ of tractors (4.8 million units) were equipped with protective structures, with 200 fatal events per year due to overturning. A study conducted in the Turkish province of Bilecik [10] showed that between 2005 and 2015, 80 fatal events occurred in agriculture, of which 58 (72.5\%) were due to tractor overturning. Twenty-four tractors were investigated for the presence of a protective structure: only 3 were fitted with a ROPS, while no ROPS was detected on the remaining 21. In an Italian region (Friuli Venezia Giulia) located in the north-east, Cividino et al. [11] detected a safety belt missing at the $55.1 \%$ of the tractor driver's seat, while the ROPS was missing only in $5.2 \%$ of the cases.

In many countries, the occupational safety authorities have for several decades imposed the fitting of protective devices against the risk of overturning. The Scandinavian countries were the first to issue mandatory regulations, with encouraging results. Springfeldt et al. [12] report that in every 100,000 tractors, the fatal overturning accidents decreased from 17 to 0.3 in Sweden and from 24 to 4 in Norway when comparing the periods 1961-1969 and 1979-1986. A similar trend also occurred in West Germany, where this value decreased from 6.7 in 1961 to 1.3 in 1986.

Even the installation in retrofit of ROPS on old tractors can improve the situation. In a recent review of 79 papers published on Scopus in the 2009-2019 period, Fargnoli et al. reported the retrofitting ROPS as the world's most relevant safety issue on older tractors [8]. In the United States, Reynolds and Groves [9] estimate that the addition of ROPS can result in a cost savings of $\$ 500,000$ and $\$ 900,000$ for each life saved, a figure comparable to actions taken in other working sectors to achieve the same goal. A cost-benefit analysis carried out in the 2-year period of 1997-1998 promoted by the Victorian Workcover Authority (Australia) to evaluate the tangible and intangible advantages of a ROPS installation campaign, reported a reduction from $24 \%$ to $7 \%$ of agricultural vehicles without ROPS, costing AU\$8 million. The estimated cost per life saved was AU\$290,000 [13]. Jones et al. [14] reported a total of 55 fatal accidents caused by tractor overturning occurred in the Australian state of Victoria from 1985 to 2010, with an average annual reduction in accidents of $7 \%$, due to both the progressive diffusion of new tractors with ROPS and the fitting in retrofit of ROPS on used tractors.

\subsection{Type of Overturning}

The majority of agricultural tractor overturning on slopes are characterized by two types of accidents. In the first type, known as a "stability loss" accident, a tractor overturns directly; in the second type, known as a "control loss" accident, a tractor is out of control prior to overturning [15].

A different criterion considers the rollover amplitude, i.e., if the machine at the end of its overturn has rolled no more than $90^{\circ}$ or was subjected to continuous rolling. In 2002, a study named "Kentucky Farm Tractor Overturn Survey" ascertained that 535 drivers reported experiencing one or more tractor overturns. Ninety-two $(17 \%)$ of the involved tractors were equipped with ROPS, but $443(83 \%)$ were not equipped. The results indicate that a ROPS-equipped tractor is more effective at stopping an overturn at $90^{\circ}$ than a nonROPS tractor, with an associated reduction in the injury severity in the event of a tractor overturning [16].

\subsection{Drivers and Job Characteristics}

An analysis of 202 agricultural tractor fatal injuries conducted from 1971 to 1981 in Georgia (US) highlighted that fatal injury rates increased with drivers' age. Nonprofessionals accounted for more than half of all tractor-associated deaths. Fatal injuries occurred mainly during the planting and harvesting months and with a peak from 4:00 
to 5:00 p.m. [17]. In the period of 2005-2014, the Forensic Pathology Department of the Centre Branch of the National Institute of Legal Medicine and Forensic Sciences of Portugal analyzed 57 fatal accidents due to tractors. The most frequent type was due to rollover, representing $38.6 \%$ of the deaths [18]. The highest number of fatalities occurred in males (89.5\% of the deaths), and $56.1 \%$ of the victims was more than 60 years old.

The driver's psycho-physical conditions are important in accident occurrence. Although the main risks seem to be related to mental stress and physical fatigue, an excessive blood alcohol level posed a significant risk. It was evidenced [18] that ethanol was detected in $24.3 \%$ of the cases, with a concentration under $0.5 \mathrm{~g} / \mathrm{L}(8.1 \%$ of the cases $)$, but $10.8 \%$ exceeding $1.2 \mathrm{~g} / \mathrm{L}$.

A survey of 47 fatal tractor accidents (79\% related to tractor rollovers) that was conducted in Croatia from 2001 to 2005 [19] revealed that 91\% of injured persons were males. The ages of $70 \%$ of the males ranged between 18 and 65 years old, and $30 \%$ were older than 65 years old. The blood alcohol level was negative in only $28 \%$ of the cases; $13 \%$ of the males had a blood alcohol concentration less than $0.50 \mathrm{~g} / \mathrm{L}$, but the remaining $87 \%$ had a concentration exceeding $0.50 \mathrm{~g} / \mathrm{L}$, with a maximum of $3.49 \mathrm{~g} / \mathrm{L}$. The average was $1.80 \mathrm{~g} / \mathrm{L}$.

\subsection{Problems with Accident Statistics}

Due to multiple reasons, many accidents occurring agriculture are not officially recorded. In Spain, a study carried out from 2005 to 2010 [20] on 388 fatal accidents involving agricultural machinery, highlighted that only $61.9 \%$ of them were correctly reported. In any case, children and non-farmers should be carefully considered.

Moreover, official statistics often classify only accidents involving professional workers, not including those that occur to other workers engaged in the agricultural sector. In fact, family members and/or seasonal workers frequently use the tractor in more or less dangerous operations. These persons, i.e., all the non-professional figures who work with the tractor in their free time (such as the hobbyists), have to be also taken into account $[11,18]$.

Again, the Spanish study [20], reported the details of 272 fatal overturning accidents: the main cause of death was the lack of a ROPS, and only in one case, the tractor was equipped with a ROPS. Among a total of 11 risk factors detected, the majority of accidents are caused by the overlapping of 3 or more of them.

\subsection{Situation in Italy}

Italy is on third place in the working tractor ranking, after the United States and Japan, with about 1.75 million units. Forty percent of them is more than 30 years old, with a low technological safety contents, in particular, regarding ROPS and safety belt equipment [21].

However, since 1974, on new traditional tractors, the fitting of ROPS in Italy is compulsory. In the 1980s and 1990s, this requirement was gradually extended to narrow-track and crawler tractors. The issue of the so called used tractor (i.e., those sold prior to 1974) was first addressed in 1981. It was definitely solved in 1996 with the publication of the guidelines "Fitting of ROPS in case of rollover of agricultural or forestry tractors" by the National Institute for Insurance Against Accidents at Work (INAIL) [22], containing detailed instructions for the manufacturing and fitting of ROPS on all used tractor categories.

An analysis carried out by INAIL in 2018 [23] concerning 312 fatal accidents that occurred in agriculture in the 5-year period of 2011-2015 reports that the main reasons of fatal events are the loss of control of agricultural machines, the absence of the ROPS and/or the seat safety belt, and, sometimes, some poor environmental conditions. The environmental conditions play an important role, especially in the accidents that occurred during the transfer task from or to the farm site. The victims were $28 \%$ self-employed or owners of farms without employees, while $18.9 \%$ were retired. The persons involved in the fatal accidents that were over 65 represent $33.8 \%$ of cases, while those between 51 and 
65 represent $29.2 \%$. Nearly three quarters (73.5\%) of accidents occurred during field work, while the remaining $26.5 \%$ of accidents occurred during transfer task.

The two main goals of this monitoring concerning the fatal overturning of agricultural tractors in Italy are to offer a further opportunity to make more effective the surveillance action carried out by the responsible bodies and to help the development of possible solutions, from technical, economic, and social points of view.

\section{Materials and Methods}

The role of the web evolved the approach to communicate information. The most significant news is systematically reported in many international, national, and local portals. Even if is not mentioned by the press at a national level, a fatal accident at work, such as a tractor overturning will not go unnoticed, as it will be reported on local web portals (of regions, municipalities, local TV, newspapers, and news sites) and on numerous blogs.

Since 2008, at DiSAA (Dipartimento di Scienze Agrarie e Ambientali) of the University of Milan-Italy an observatory dedicated to the monitoring of fatal accidents due to tractor overturning was established. By examining many web portals of news and information, the fatal tractor overturning accidents were systematically recorded, in order to extract the maximum level of detail. The information obtained were used to construct a truthful, effective, and timely scenario of the situation.

\subsection{Strengths of the Study}

The most important added values of the described method are:

- maximum timeliness in the monitoring of the accidents;

- $\quad$ a reduced commitment of resources;

- $\quad$ an acceptable approximation.

\subsection{Limitations of the Study}

However, the method suffers from some limitations:

- the obtained statistics show values that could not completely reflect reality. For example, some fatal events could be missed, because the tractor overturning causes at a first step serious injuries to the driver, and only after a period of time, the involved person dies, but the news is no longer reported;

- it cannot be systematic, as the details level of the reported events should be not completely congruent. For example, the working position of the victims (professional or non-professionals) is not usually reported;

- $\quad$ it may sometimes suffer from the press inaccuracies.

The present survey included the fatal accidents involving the overturning of agricultural tractors that occurred in Italy in the 12-year period from 2008 and 2019, detected on the web and classified based on a given set of criteria (Table 1).

Table 1. Details of the set of criteria used for the classification of the overturning accidents of agricultural tractors.

\begin{tabular}{cc}
\hline Data & Detail \\
\hline Date & Year, month, and day \\
Site & Region, province, and municipality \\
Driver & Gender, age, and nationality \\
Passenger & Number \\
Activity & Field task and road transfer \\
Tractor characteristics & Wheeled and crawler \\
ROPS type & Cab, 4-pillar frame, 2-pillar frame, etc. \\
\hline
\end{tabular}

The survey was based on the Google search engine, by filtering the results according to the date of publication of the news. By entering suitable keywords, such as "dead tractor," 
"tractor accident," and "tractor overturning," the first ten pages returned by the search engine were examined, classifying the fatal overturning accidents according to the criteria described above. In case of inconsistencies in the news, the most frequently reported data were considered to be true or that coming from the most reliable source(s) of information.

\section{Results and Discussion}

\subsection{Results}

In the 12 years surveyed, the DiSAA observatory recorded 1414 fatal accidents, corresponding to an average of about 118 fatal events per year, with a minimum of 102 in 2017 and a maximum of 145 in 2011 (Figure 1).

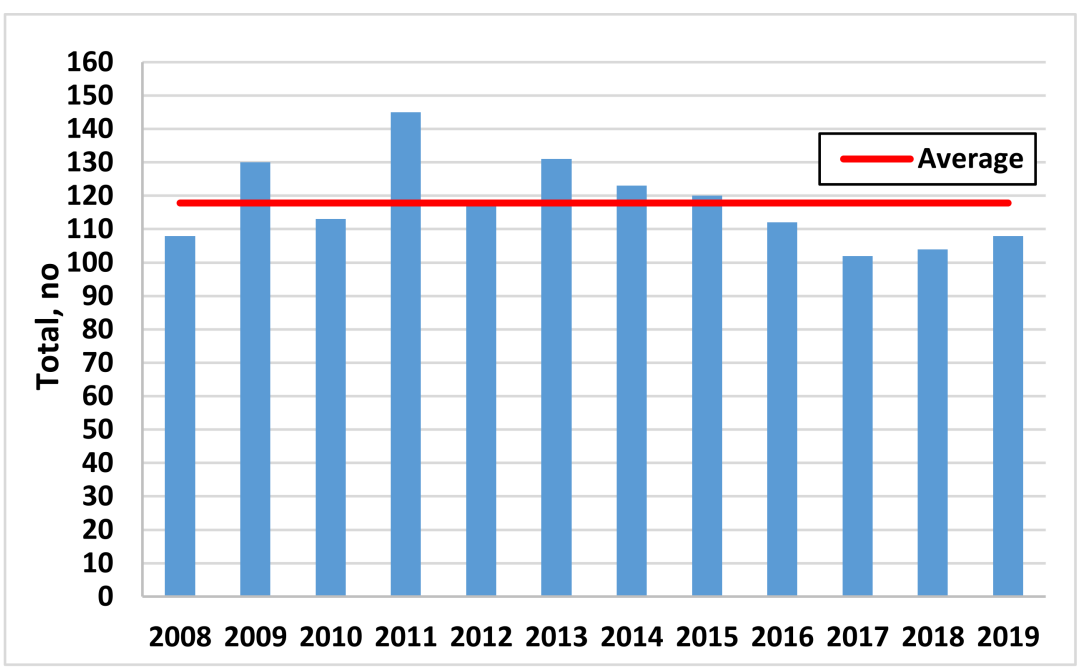

Figure 1. Fatal agricultural tractor overturning occurred in Italy from 2008 to 2019.

No clear trend was found; despite the recent prevention actions promoted by the bodies in charge, unfortunately there is no consolidated decrease in cases.

As expected, the majority of accidents occurred in the spring and summer months, when the field work is more intense (Figure 2).

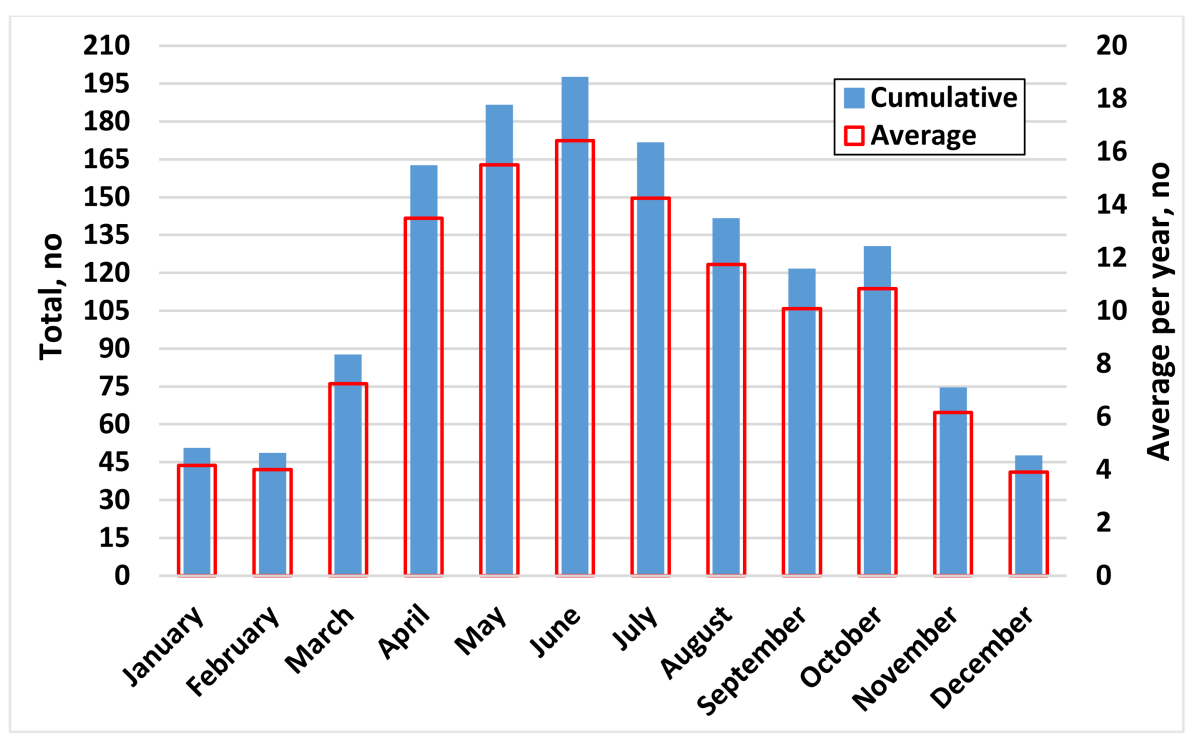

Figure 2. Cumulative and average monthly trend of fatal overturning of the agricultural tractors, occurred in Italy from 2008 to 2019. 
The days of the week with the highest fatal overturning accidents number are Tuesday, with 222 events and Friday with 217. Despite this, 208 cases were recorded on Saturday as well as 158 fatal events on Sunday. In 11 cases out of the 1414 totals $(0.8 \%)$, the day of occurrence was not detected (Figure 3).

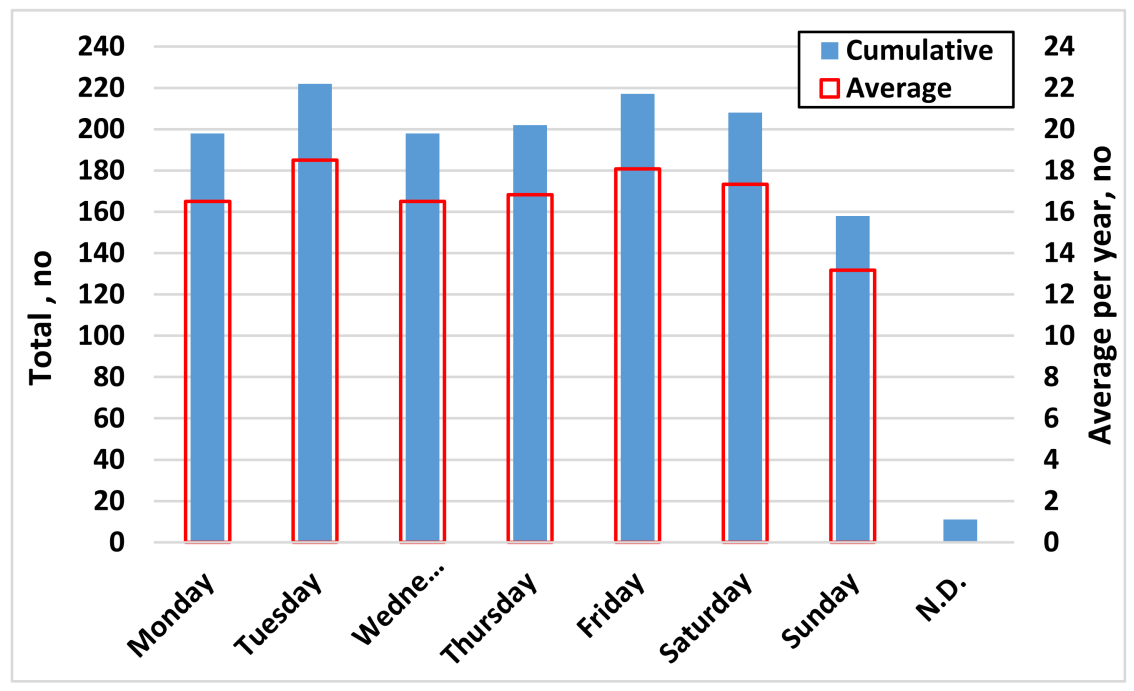

Figure 3. Fatal overturning of the agricultural tractors occurred in Italy from 2008 to 2019, classified according to the day of the week of occurrence (N.D. = not detected).

As expected, the regions where farming is prevalent are those most affected by fatal accidents (Tuscany, Emilia Romagna, and Veneto) (Figure 4).

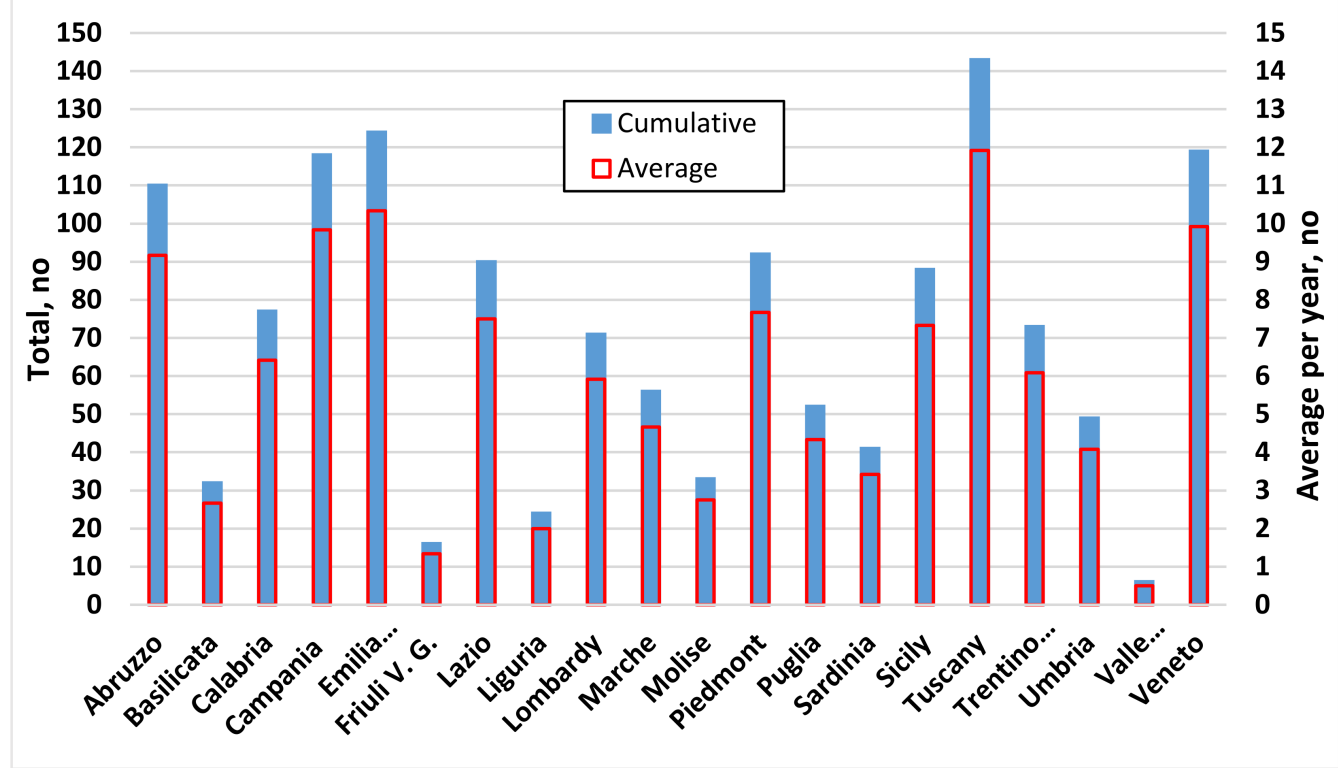

Figure 4. Region of occurrence of fatal overturning of agricultural tractors, from 2008 to 2019.

In some cases, large cultivated areas of hilly and sloping terrain seem to be a factor of the increase in the overturning risk (Abruzzo, Calabria, and Piedmont). Many fatal accidents in other regions are most likely attributed to old and worn tractor fleet (Campania and Abruzzo). Of a total of 1414 accidents, 525 (37.1\%) accidents occurred in northern Italy, $481(34.0 \%)$ accidents occurred in central Italy, and $408(28.9 \%)$ accidents occurred in southern Italy. 
Obviously, the absolute figures do not properly clarify the situation. Therefore, the data obtained were also compared with other typical figures of agricultural activity. The relationship between fatal events and the number of employees in agriculture (according to official data of ISTAT, Italian National Institute of Statistics [24,25]) shows that Molise and Abruzzo are confirmed among the most dangerous regions, to which must be added Valle d'Aosta, Liguria, and Tuscany (Figure 5).

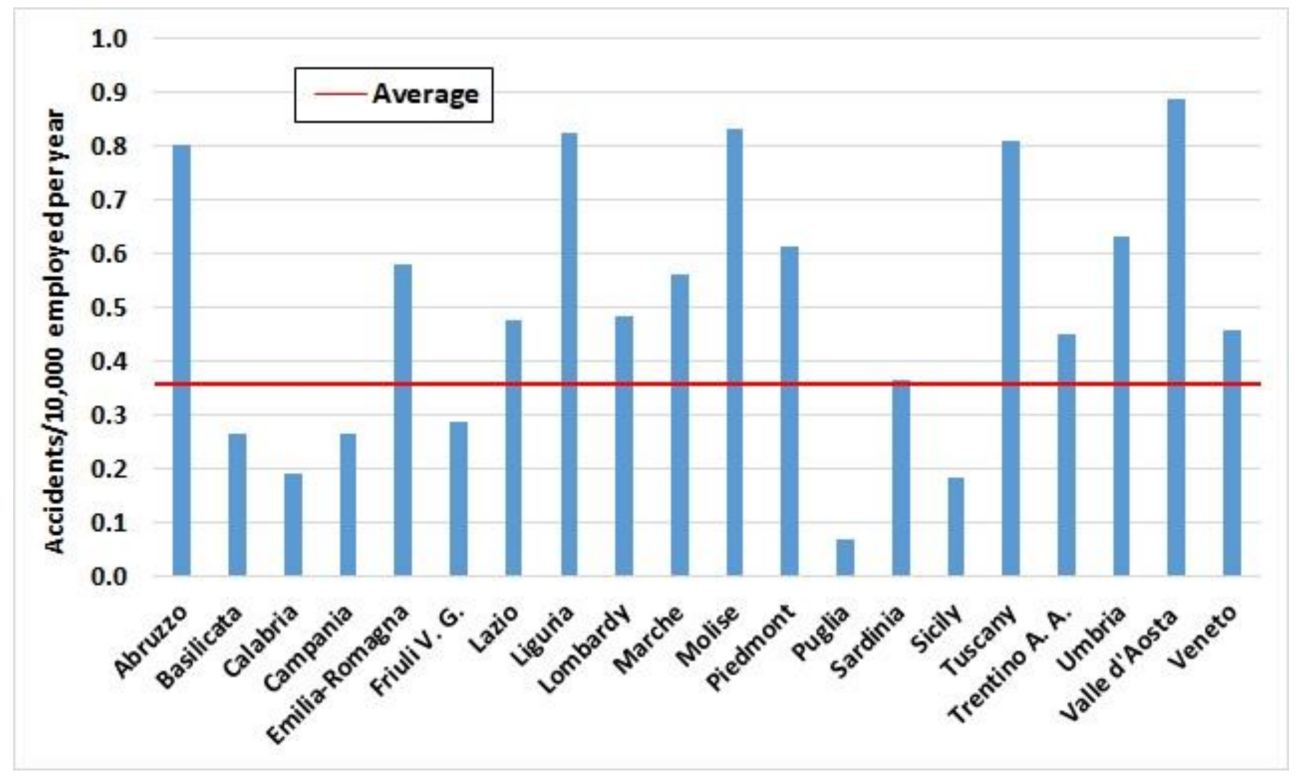

Figure 5. Annual average of fatal accidents due to overturning of agricultural tractors per 10,000 employed per year, divided by region, in the period of 2008-2019.

On the other hand, if the Useful Agricultural Area (UAA) is taken into consideration [24-26], Liguria shows a very high number of victims due to tractor overturning, with almost 55 cases per 100,000 ha, well above the national average (Figure 6). This figure could be justified by the many small fruit, vegetable, and flower farms working in this region, which have a remarkable amount of hilly and mountainous areas. Abruzzo and Campania follow, respectively, with 24 and 21 cases per 100,000 ha of UAA, while Tuscany and Trentino-Alto Adige are under 20 victims per 100,000 ha of UAA. Although above the national average, the data referring to Tuscany are relatively low. The high number of fatal accidents recorded in the considered period (143) is spread over a considerable UAA.

Figure 7 shows the comparison among regions of the number of fatal accidents per $10,000,000 \mathrm{~h}$ of work of those employed in agriculture. The ratio is less than 1 for almost all Italian regions, with the exception of Abruzzo, Umbria, Molise, and Tuscany. The working hours were obtained by multiplying the working days retrieved from the ISTAT database [24] and the conventional data of $8 \mathrm{~h} /$ day. The ISTAT figure refers to the working days of all the employed in agriculture, therefore, also of those employees who do not work with the tractor, in tasks such as pruning or manual harvesting of fruits and vegetables. As a consequence, the data of some regions, such as Puglia, Sicily, and Sardinia, could be underestimated. 


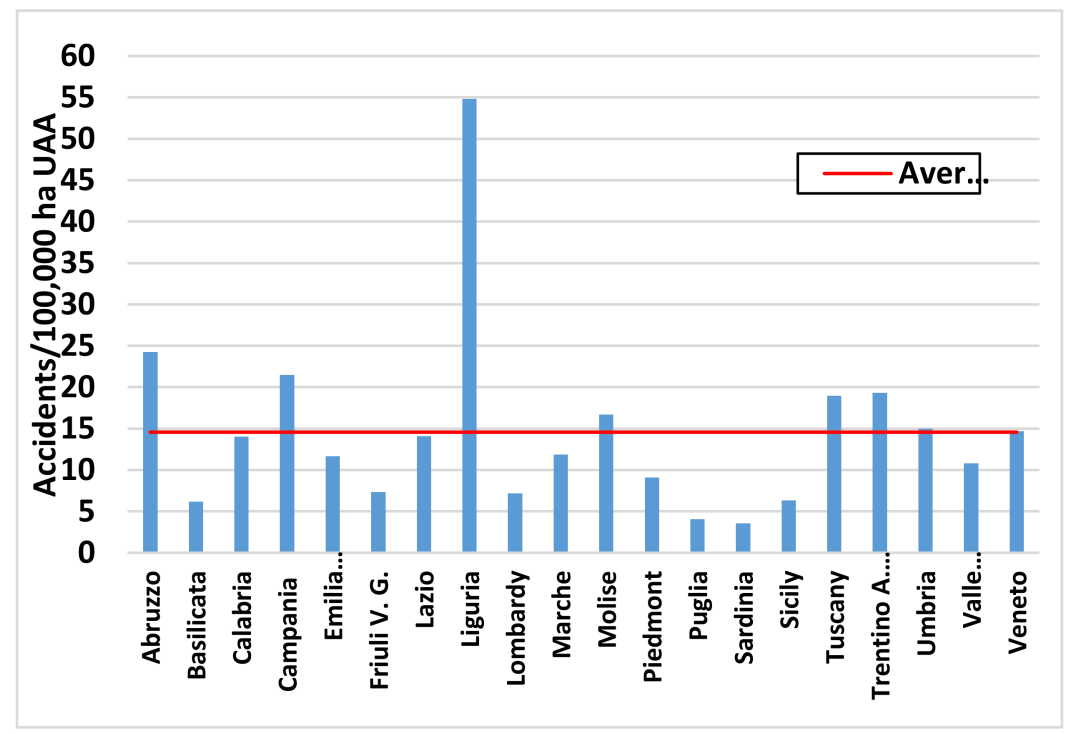

Figure 6. Fatal overturning of agricultural tractors per 100,000 ha Useful Agricultural Area (UAA), divided by region, in the period of 2008-2019.

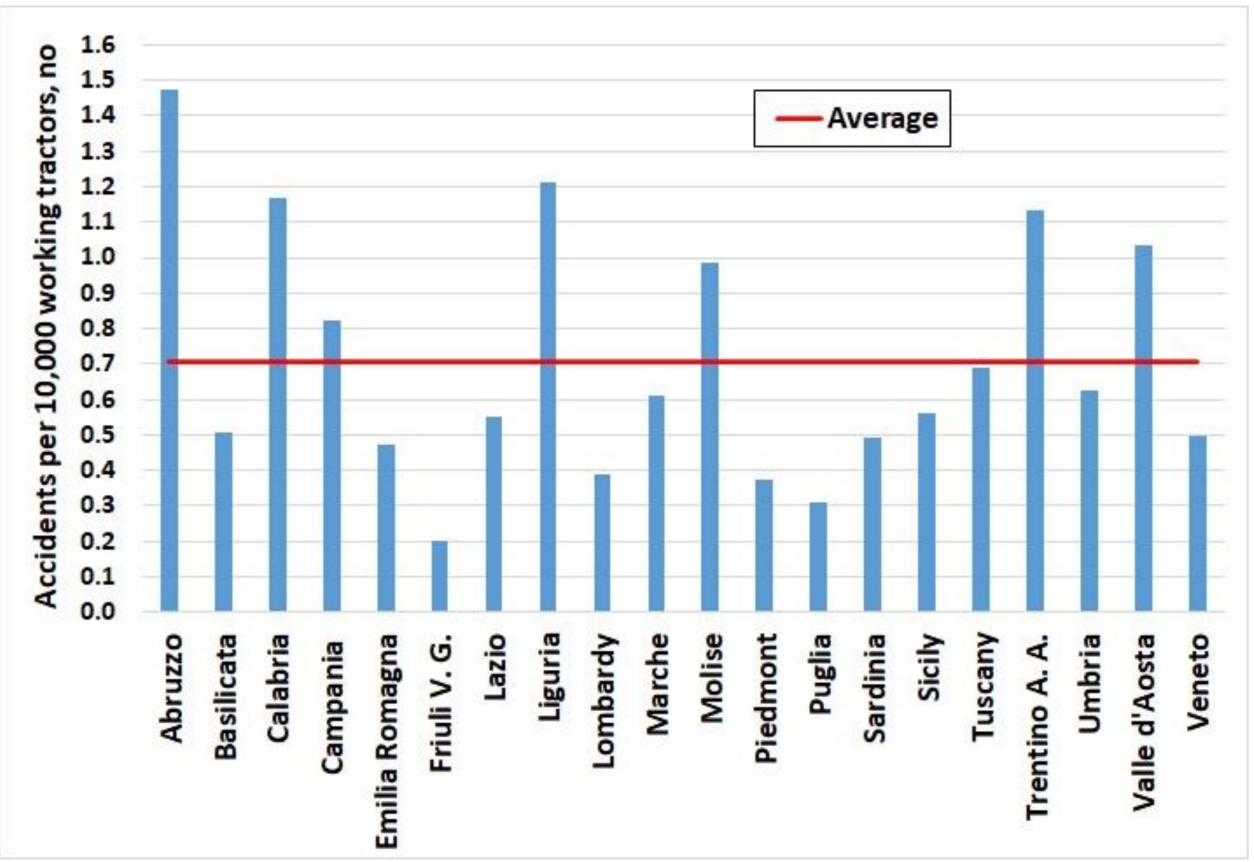

Figure 7. Fatal overturning of agricultural tractors per 10,000,000 $\mathrm{h}$ worked, divided by region, in the period of 2008-2019.

The data of accidents due to overturning were then compared with the number of tractors operating in the Italian regions, thanks to the data provided by FederUnacoma (National Federation of Agricultural Machinery Manufacturers) [27] (Figure 8). Against a national average of 0.71 deaths $/ 10,000$ tractors, the regions with the highest ratios are Abruzzo (1.47 victims/10,000 tractors), Liguria (1.21), and Calabria (1.17). The large area on slopes dedicated to vineyards and orchards must be associated in these cases with an obsolete tractor fleet, including many machines still lacking ROPS and safety belts. 


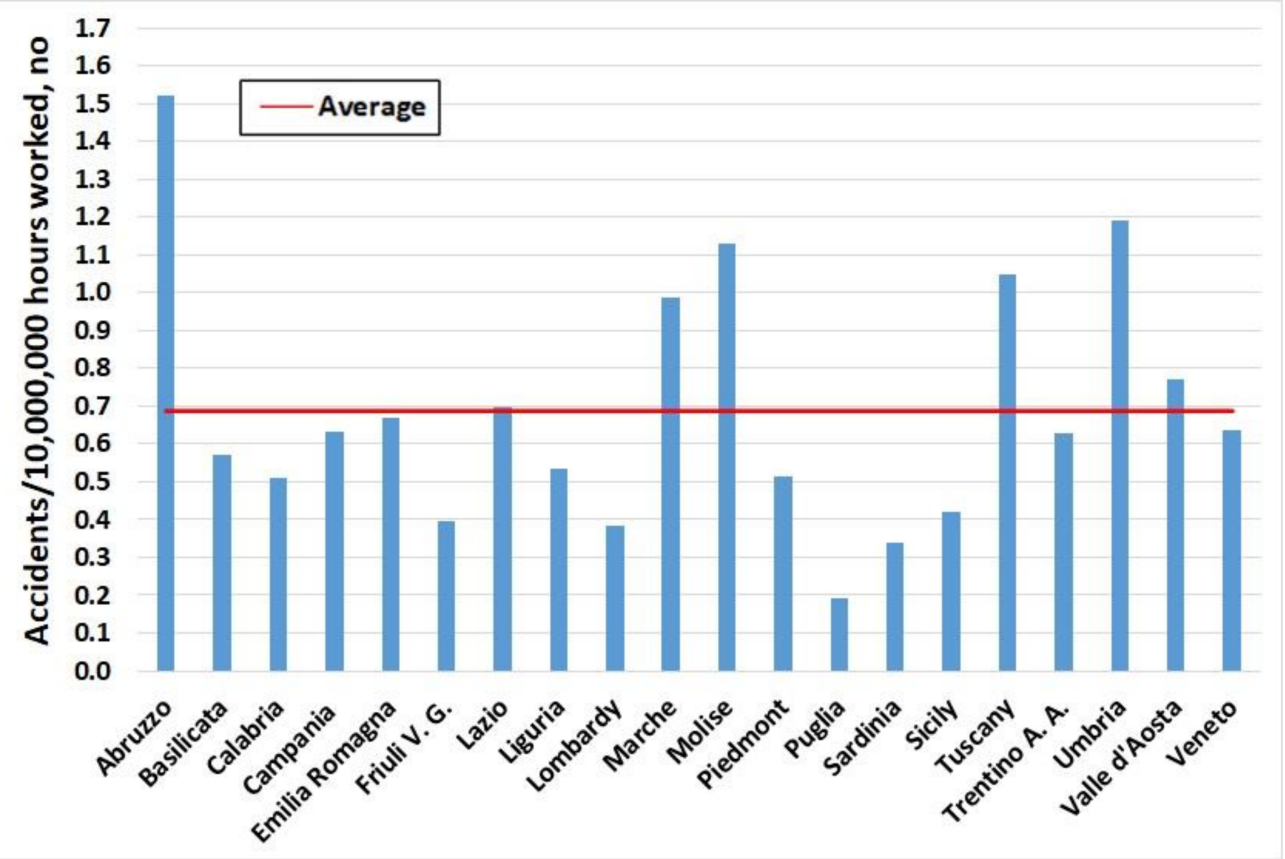

Figure 8. Fatal overturning of agricultural tractors per 10,000 working tractors, divided by region, in the period of 2008-2019.

The 61-70 and 71-80 age classes recorded the highest number of victims (320 and 356, respectively) in the investigated period, representing almost half $(47.8 \%)$ of the total of 1414 recorded accidents (Figure 9). Sadly, 8 victims were reported in the youngest age class $(0-14)$; in all cases, the kids were travelling as passengers on the tractor, together with an adult. For 31 victims ( $2.2 \%$ of the total), it was not possible to detect the age.

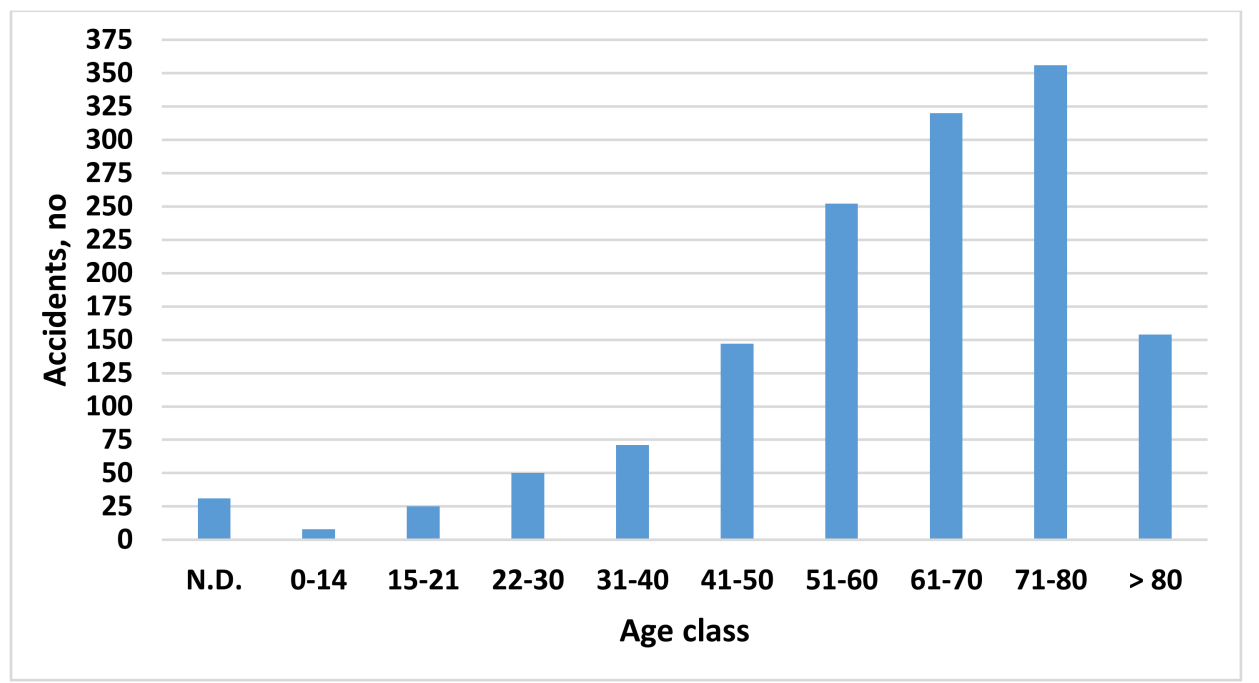

Figure 9. Victims of fatal overturning of agricultural tractors in Italy, divided in age classes, in the period of 2008-2019.

In the great majority of the overturning accidents (1395), the victims have been male, while only 9 have been female. The majority of fatal events (1361) involved Italian persons; 23 employees were Romanian, while the remaining victims were coming from EU (6) and non-EU (19) countries. In 5 cases, the nationality of the persons involved was not detected. 
In 1240 cases $(87.7 \%$ of the total), the task carried out at the time of the accident was ascertained: $71.4 \%$ (885) occurred in the field, and $18.9 \%(234)$ in the transfer from the farm to the field (or vice versa). The remaining 9.7\% (121) fatal events occurred on public roads.

Most of the tractors involved (585 cases) in fatal accidents were wheeled (83.5\%), while for the remaining $16.5 \%$ (116 cases), the tractors were crawled. The result is consistent with what is expected, taking into account the lower diffusion of tracked vehicles and their higher structural stability. In about half (713) of the recorded accidents, such data were not detected, due to a lack of detail in the news published on the web. Only in 434 fatal overturning accidents (30.7\% of the total), the type of ROPS fitted was classified (Figure 10).

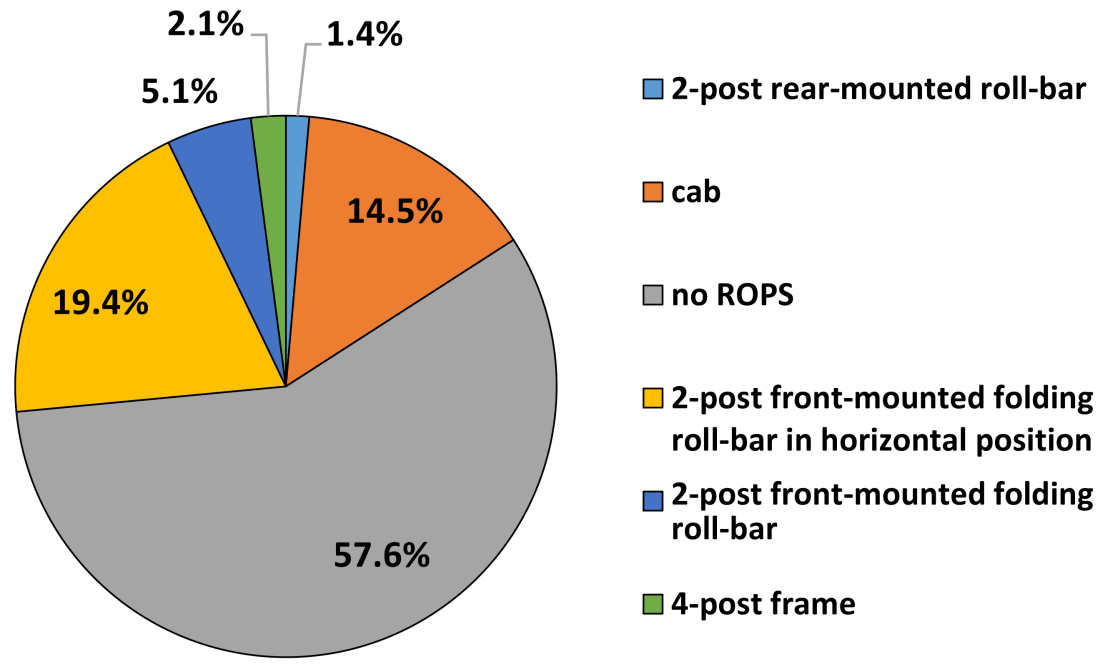

Figure 10. Fatal tractor overturning accidents classified according to the type of rollover protective structures (ROPS) installed (434 ROPS type detected case out of 1414 total fatal accident), occurred in Italy in the period of 2008-2019.

In 250 cases (57.6\%), the tractors had no ROPS, while $84(19.4 \%)$ were fitted with a folding front two-post roll-bar, which, however, was in a horizontal position, therefore ensuring no protection in case of overturning. Of the tractors surveyed, $14.5 \%$ had a cab, while the remaining $3.5 \%$ were fitted with a roll-bar with two rear or four posts.

\subsection{Discussion}

In the 12 years of the investigated period (from 2008 to 2019) no clear trend, hopefully decreasing, was detected about the fatal overturning accidents of agricultural tractors in Italy. Only between 2013 and 2017 a slight, but constant, decrease was registered, probably due to the initial effect of the introduction in 2012 of the obligation to acquire the Tractor Training Certificate (TTC), finalized to properly train the operators on the risks in using the tractors and to manage the machine safely. However, unfortunately, the data collected in the most recent 3 years of investigation show, on the contrary, a new slight increase.

Considering the month of occurrence of the fatal accidents, and in accordance to what found by Antunes et al. [18] and Erkol et al. [7], most of them occurred when the agricultural activity is more intense. In detail, in our investigation 197 (16.4\% on average) occurred in June, followed by May (186, average $15.5 \%$ ) and July (171, average 13.4\%). As expected, the months in which fewer fatal overturning accidents occur are the winter months, i.e., January, February, and December, with 50, 48, and 47 total victims, respectively. Frequent fatalities occur even in the cold months, confirming that the tractor is a machine used all year round, even when the fields and roads are often in poor conditions for climatic reasons. 
A remarkable number of fatal overturning accidents occurred in the weekend days (Saturday and Sunday), confirming that for farmers this time is not a free time, especially when urgent tasks must be completed as soon as possible due to uncertain climatic conditions. Moreover, the weekend days are primarily taken advantage of the non-professional and part-time manpower for their field activity. Other reasons of this occurring could be the skill level of these worker categories and the maintenance conditions of the tractors they use, being them both generally poor.

On the other hand, other investigations [28,29] concluded that there is a strong need to increase the skill of the non-professional tractor drivers, above all what concerns the risk of overturning. Unfortunately, the characteristics of the investigation of the present survey (i.e., the level of information obtained) did not allow the classification of the victims between professional and non-professional (retired and part-time) workers.

In Italy, $41.6 \%$ of the territory is classified as hilly, $35.2 \%$ is classified as mountain, and only the remaining $23.2 \%$ is flat land [25]. The regions having a large part of the agricultural area located in the hills and mountains highlighted the major part of the fatal accidents, so the work on slopes is confirmed as the main reason of fatal accident, being the poor dynamic stability condition recognized as the most powerful factor to cause an overturning $[2,7,8,18,30]$.

Almost half of the victims of the present survey (47.8\%) was between 61 and 80 , in accordance with the old average age of the agricultural workers in Italy. This figure reflects what was previously found $[4,18]$, i.e., mature employees are subject to a higher risk of overturning. In addition to their old age, these persons often work with old and worn tractors, often not equipped with ROPS and seat belts. Always in our study, the number of victims over 80 years old is also significant, being $11.1 \%$ of the total.

Contrary to what occurs in other sectors, in agriculture, the work is extended well beyond retirement, especially in a family context [11]. In contrast, although the overall range is generally very wide, in other studies, a consistently lower average age of the victims of fatal tractor overturning accidents was found, being about 32 [2] and 42 [7] years old, probably reflecting the character of the manpower in the surveyed country. Sadly, in our study, a total of 8 victims were reported in the youngest age class defined in our study (0-14); in all cases, the kids were travelling as passengers on the tractor, together with an adult. In fact, in Italy, the transportation of person(s) on board of a tractor is generally forbidden; however, it is allowed only when travelling on public roads and if a dedicated seat is provided for the passenger. In contrast, in other countries, a high number of victims were detected among tractor passengers. Dogan et al. [2] reported tractor-related fatalities involving the passengers in $43 \%$ of the cases taken into-account, while the drivers were involved in 39.5\% only. In addition, Antunes et al. [18] reported a relatively low number of drivers $(45.9 \%)$ involved in fatal tractor accidents.

In our survey, almost all the victims (98.7\%) were male; other similar investigations $[2,18]$ confirmed this trend, evidencing what stated by Jahdav et al. [31], i.e., that males have a higher risk of injury from machinery.

In $57.6 \%$ of the detected fatal accident of our study carried out in Italy, the tractors were missing the ROPS. This represents a very critical situation, fully confirmed by similar surveys carried out in Turkey (95.3\% of ROPS missing) [2] and again in Italy (71.7\% of ROPS missing) [3]. On the other hand, another survey conducted in 161 farms located in northern Italy [11] evidenced, although at a local level, a low number of cases of ROPS missing (5.1\% only), even if at the same time, the safety belt was missing in $55.1 \%$ of the cases registered. This represents a very critical situation, because the ROPS is regularly fitted on the tractor, but the protection provided by this device in the described condition is very close to zero.

In detail, in our survey, $19.4 \%$ of the fatal accidents recorded that the tractors involved were fitted with a folding front two-post roll-bar fixed in a horizontal position, therefore, ensuring no protection in case of overturning. This is substantially due to negligence or carelessness of the drivers, who do not consider properly its safety role, or to other actual 
difficulties in folding/rising the protective structure, because of poor design or inconsistencies with human anthropometrics requiring awkward position or movements [32]. To try to solve this problem, a research work was carried out in order to design a nonfoldable ROPS for narrow-track tractors, which provides rollover protection all the time without making agricultural works more difficult. For this purpose, a reverse engineering methodology was adapted, following bottom-up and top-down approaches [33]. Moreover, in 5.1\% of cases, the front two-post roll-bar was detected in a regular (vertical) protective position, but the accidents had fatal issue because the drivers were probably not secured to the driver's seat with the safety belt, so they were thrown out and subsequently hit fatally by one or more parts of the tractor.

\section{Conclusions}

Notwithstanding most agricultural injuries are due to errors in the systems of safety, it was ascertained that not only training [34] and personal protective equipment but also regulation of safety design, inspection/maintenance of workplaces, and mitigation devices play an important role in preventing agricultural injuries [35]. Regarding the mitigation devices, the research on protective systems of tractors is largely characterized by studies on ROPS, including those new types aimed at preventing the unsafe behavior of users, such as the AutoROPS, and the compact rollover protective structure (CROPS) [8]. Moreover, also the safety pictorials could help to improve the situation, even if a strong need for training courses focusing on these pictorials and their meanings, as well as the improvement in the comprehension of the pictorials themselves, as several studies have pointed out [27,28,36-38], about two million tractors are working in Italy; $89 \%$ of tractors are over 10 years old, and their average life span is about 26 years. This situation involves serious problems of efficiency, reliability, and, above all, safety.

Many actions are needed to try to improve the situation.

The recent introduction in Italy of the Tractor Training Certificate (TTC), which includes theoretical and practical tests, allows operators to be properly trained on the risks in using the tractors and to manage the machine safely. After 5 years from obtaining TTC, a refresher training is provided. However, the legislation suffers at the moment from a major handicap, because the so-called hobbyists (i.e., the non-professional persons) are excluded from the compulsory training and also no specific training is required to drive the tractor in road traffic.

Another opportunity to improve the situation is the introduction of the periodical inspection, to verify the technical requirements of the used tractors, also from the safety point of view. Thanks to the coming in force of the European Directive 2014/45/EC, a series of deadlines for starting the service in Italy was finally defined, after several extensions. The inspection will probably eliminate old and worn (i.e., dangerous) machines from the national tractor fleet. This hopefully should lead to a decrease in fatal overturning accidents.

Another action that could have positive effects, promoted by INAIL [39], concerns the issuing of the so-called tractor bonus, a significant financial support to encourage the purchasing of modern tractors by small farms and/or young farmers.

Finally, considering the increase in the age of tractor drivers and the reduction in the manpower in the agricultural sector, a valuable resource could be represented by the non-EU workers, correctly regulated in compliance with current regulations, provided that the foreign persons have been properly instructed and trained to safely manage the tractor, also when Italian language skill is poor [40,41].

Author Contributions: Conceptualization, D.F. and D.P.; data curation, D.F., S.S. and L.E.G.; formal analysis, D.F. and S.S.; investigation, S.S. and L.E.G.; methodology, D.F. and D.P.; project administration, D.F. and D.P.; resources, D.F.; supervision, D.F., S.S. and D.P.; validation, S.S., L.E.G. and D.P.; visualization, D.F., S.S. and D.P.; writing-original draft, D.F., S.S. and D.P.; writing-review and editing, D.F. and D.P. All authors have read and agreed to the published version of the manuscript. 
Funding: This research received no external funding.

Institutional Review Board Statement: Not applicable.

Informed Consent Statement: Not applicable.

Data Availability Statement: Not applicable.

Conflicts of Interest: The authors declare no conflict of interest.

\section{References}

1. INAIL. Banca Dati Statistica. Available online: https://bancadaticsa.inail.it/bancadaticsa/login.asp (accessed on 8 April 2021).

2. Dogan, K.H.; Demirci, S.; Sunam, G.S.; Deniz, I.; Gunaydin, G. Evaluation of Farm Tractor-Related Fatalities. Am. J. Forensic Med. Pathol. 2010, 31, 64-68. [CrossRef]

3. Rondelli, V.; Casazza, C.; Martelli, R. Tractor rollover fatalities, analyzing accident scenario. J. Saf. Res. 2018, 67, 99-106. [CrossRef] [PubMed]

4. Myers, J.R.; Hendricks, K.J. Agricultural tractor overturn deaths: Assessment of trends and risk factors. Am. J. Ind. Med. 2009, 53, 662-672. [CrossRef]

5. Helmkamp, J.; Lundstrom, W. \#56 Tractor-related deaths among west virginia farmers. Ann. Epidemiol. 2002, 12, 510. [CrossRef]

6. Türkoğlu, A.; Sehlikoğlu, K.; Tokdemir, M. Analysis of Tractor-Associated Fatalities. Am. J. Forensic Med. Pathol. 2017, 38, 306-311. [CrossRef] [PubMed]

7. Erkol, Z.; Büken, B.; Hekimoğlu, Y.; Erkol, H.; Ince, H.; Erzengin, Ö.U. Analysis of Tractor-Related Deaths. J. AgroMed. 2013, 18, 87-97. [CrossRef]

8. Fargnoli, M.; Lombardi, M. Safety Vision of Agricultural Tractors: An Engineering Perspective Based on Recent Studies (20092019). Safety 2019, 6, 1. [CrossRef]

9. Reynolds, S.J.; Groves, W. Effectiveness of roll-over protective structures in reducing farm tractor fatalities. Am. J. Prev. Med. 2000, 18, 63-69. [CrossRef]

10. Darçin, E.S.; Darcin, M. Fatal tractor injuries between 2005 and 2015 in Bilecik Turkey. Biomed. Res. 2017, 28, 549-555.

11. Cividino, S.R.S.; Pergher, G.; Zucchiatti, N.; Gubiani, R. Agricultural Health and Safety Survey in Friuli Venezia Giulia. Agriculture 2018, 8, 9. [CrossRef]

12. Springfeldt, B. Rollover of tractors-International experiences. Saf. Sci. 1996, 24, 95-110. [CrossRef]

13. Day, L.; Rechnitzer, G.; Lough, J. An Australian experience with tractor rollover protective structure rebate programs: Process, impact and outcome evaluation. Accid. Anal. Prev. 2004, 36, 861-867. [CrossRef]

14. Jones, C.B.; Day, L.; Staines, C. Trends in tractor related fatalities among adults working on farms in Victoria, Australia, 1985-2010. Accid. Anal. Prev. 2013, 50, 110-114. [CrossRef] [PubMed]

15. Hunter, A.; Owen, G. Tractor overturning accidents on slopes. J. Occup. Accid. 1983, 5, 195-210. [CrossRef]

16. Myers, M.L.; Cole, H.P.; Westneat, S.C. Injury severity related to overturn characteristics of tractors. J. Saf. Res. 2009, 40, 165-170. [CrossRef]

17. Goodman, R.A.; Smith, J.D.; Sikes, R.K.; Rogers, D.L.; Mickey, J.L. Fatalities associated with farm tractor injuries: An epidemiologic study. Public Health Rep. 1985, 100, 329-333. [PubMed]

18. Antunes, S.M.; Cordeiro, C.; Teixeira, H.M. Analysis of fatal accidents with tractors in the Centre of Portugal: Ten years analysis. Forensic Sci. Int. 2018, 287, 74-80. [CrossRef] [PubMed]

19. Gassend, J.; Bakovic, M.; Mayer, D.; Strinovic, D.; Skavic, J.; Petrovecki, V. Tractor driving and alcohol—A highly hazardous combination. Forensic Sci. Int. Suppl. Ser. 2009, 1, 76-79. [CrossRef]

20. Arana, I.; Mangado, J.; Arnal, P.; Arazuri, S.; Alfaro, J.R.; Jaren, C. Evaluation of risk factors in fatal accidents in agriculture. Span. J. Agric. Res. 2010, 8, 592. [CrossRef]

21. Cavallo, E.; Ferrari, E.; Bollani, L.; Coccia, M. Attitudes and behaviour of adopters of technological innovations in agricultural tractors: A case study in Italian agricultural system. Agric. Syst. 2014, 130, 44-54. [CrossRef]

22. INAIL. L'installazione dei Dispositivi di Protezione in Caso di Ribaltamento nei Trattori Agricoli o Forestali Linee Guida. Available online: https:/ / www.inail.it/cs/internet/comunicazione/pubblicazioni/catalogo-generale/linstallazione-dei-dispositivi-diprotezione.html (accessed on 8 April 2021).

23. INAIL. Sistema di Sorveglianza Degli Infortuni Mortali e Gravi sul Lavoro: Gli Infortuni Mortali in Agricoltura, Scheda 12. Conferenza Delle Regioni e Delle Province Autonome. Available online: https://www.inail.it/cs/internet/docs/alg-informo-gliinfortuni-mortali-agricoltura_6443124234744.pdf (accessed on 8 April 2021).

24. ISTAT. Database. Available online: http:/ / dati.istat.it/ (accessed on 8 April 2021).

25. ISTAT. Annuario Statistico Italiano 2019, Capitolo 1 Territorio. Available online: https://www.istat.it/it/files//2019/12/Asi-20 19.pdf (accessed on 8 April 2021).

26. ISTAT. Censimento Agricoltura 2010. Available online: http://dati-censimentoagricoltura.istat.it/Index.aspx (accessed on 8 April 2021).

27. FederUnacoma, Ufficio Studi e Statistiche FederUnacoma. Available online: https:/ /www.federunacoma.it (accessed on 8 April 2021). 
28. Caffaro, F.; Mirisola, A.; Cavallo, E. Safety signs on agricultural machinery: Pictorials do not always successfully convey their messages to target users. Appl. Ergon. 2017, 58, 156-166. [CrossRef] [PubMed]

29. Pessina, D.; Facchinetti, D.; Giordano, D.M. Narrow-Track Agricultural Tractors: A Survey on the Load of the Hand-Operated Foldable Rollbar. J. Agric. Saf. Heal. 2016, 22, 275-284. [CrossRef]

30. Kogler, R.; Quendler, E.; Boxberger, J. Occupational Accidents with Agricultural Machinery in Austria. J. AgroMed. 2015, 21, 61-70. [CrossRef] [PubMed]

31. Jadhav, R.; Achutan, C.; Haynatzki, G.; Rajaram, S.; Rautiainen, R. Risk Factors for Agricultural Injury: A Systematic Review and Meta-Analysis. J. AgroMed. 2015, 20, 434-449. [CrossRef]

32. Cremasco, M.M.; Caffaro, F.; Giustetto, A.; Vigoroso, L.; Paletto, G.; Cavallo, E. Tractor Rollover Protection: Is the Incorrect Use of Foldable Rollover Protective Structures Due to Human or to Technical Issues? Hum. Factors J. Hum. Factors Ergon. Soc. 2019, 62, 64-76. [CrossRef]

33. Fargnoli, M.; Vita, L.; Gattamelata, D.; Laurendi, V.; Tronci, M. A reverse engineering approach to enhance machinery design for safety. In Proceedings of the 12th International Design Conference, Dubrovnik, Croatia, 21-24 May 2012; Marjanovic, D., Storga, M., Pavkovic, N., Bojcetic, N., Eds.; International Design Conference: Dubrovnik, Croatia, 2012; pp. 627-636. Available online: https://www.designsociety.org/publication/32030/A+REVERSE+ENGINEERING+APPROACH+TO+ENHANCE+ MACHINERM+DESIGN+FOR+SAFETY (accessed on 8 April 2021).

34. Fargnoli, M.; Lombardi, M.; Haber, N.; Puri, D. The Impact of Human Error in the Use of Agricultural Tractors: A Case Study Research in Vineyard Cultivation in Italy. Agriculture 2018, 8, 82. [CrossRef]

35. Kim, H.; Lee, K.; Räsänen, K. Agricultural injuries in Korea and errors in systems of safety. Ann. Agric. Environ. Med. 2016, 23, 432-436. [CrossRef]

36. Caffaro, F.; Schmidt, S.; Murphy, D.J.; Cavallo, E. Comprehension rates of safety pictorials affixed to agricultural machinery among Pennsylvania rural population. Saf. Sci. 2018, 103, 162-171. [CrossRef]

37. Vigoroso, L.; Caffaro, F.; Cremasco, M.M.; Bagagiolo, G.; Cavallo, E. Comprehension of Safety Pictograms Affixed to Agricultural Machinery among Pakistani Migrant Farmworkers in Italy. J. AgroMed. 2020, 25, 265-278. [CrossRef] [PubMed]

38. Bagagiolo, G.; Vigoroso, L.; Caffaro, F.; Cremasco, M.M.; Cavallo, E. Conveying Safety Messages on Agricultural Machinery: The Comprehension of Safety Pictorials in a Group of Migrant Farmworkers in Italy. Int. J. Environ. Res. Public Health 2019, 16, 4180. [CrossRef]

39. INAIL. Bando ISI Agricoltura 2019-2020, Delibera del 25 Giugno 2020, n. 27. Available online: https://www.inail.it/cs/internet/ attivita/prevenzione-e-sicurezza/agevolazioni-e-finanziamenti/incentivi-alle-imprese/bando-isi-agricoltura-2019-2020.html (accessed on 8 April 2021).

40. Vigoroso, L.; Caffaro, F.; Cavallo, E. Occupational safety and visual communication: User-Centred design of safety training material for migrant farmworkers in Italy. Saf. Sci. 2020, 121, 562-572. [CrossRef]

41. Caffaro, F.; Cremasco, M.M.; Bagagiolo, G.; Vigoroso, L.; Cavallo, E. Effectiveness of occupational safety and health training for migrant farmworkers: A scoping review. Public Health 2018, 160, 10-17. [CrossRef] [PubMed] 